\title{
Use of surface waves for geotechnical engineering applications in Western Sydney
}

\author{
K. Tokeshi ${ }^{1}$, P. Harutoonian ${ }^{2}$, C. J. Leo ${ }^{2}$, and S. Liyanapathirana ${ }^{2}$ \\ ${ }^{1}$ Institute for Infrastructure Engineering, University of Western Sydney, Locked Bag 1797, Penrith NSW 2751, Australia \\ ${ }^{2}$ School of Computing, Engineering and Mathematics, University of Western Sydney, Locked Bag 1797, Penrith NSW 2751, \\ Australia
}

Correspondence to: K. Tokeshi (k.tokeshi@uws.edu.au)

Received: 19 February 2013 - Accepted: 15 May 2013 - Published: 27 June 2013

\begin{abstract}
Current in situ methods used to geotechnically characterize the ground are predominantly based on invasive mechanical techniques (e.g. CPT, SPT, DMT). These techniques are localized to the tested area thus making it quite time consuming and costly to extensively cover large areas. Hence, a study has been initiated to investigate the use of the non-invasive Multichannel Analysis of Surface Waves (MASW) and Multichannel Simulation with One Receiver (MSOR) techniques to provide both an evaluation of compacted ground and a general geotechnical site characterization. The MASW technique relies on the measurement of active ambient vibrations generated by sledgehammer hits to the ground. Generated vibrations are gathered by interconnected electromagnetic geophones set up in the vertical direction and in a linear array at the ground surface with a constant spacing. The MSOR technique relies on one sensor, one single geophone used as the trigger, and multiple impacts are delivered on a steel plate at several distances in a linear array. The main attributes of these non-invasive techniques are the cost effectiveness and time efficiency when compared to current in situ mechanical invasive methods. They were applied to infer the stiffness of the ground layers by inversion of the phase velocity dispersion curves to derive the shear wave velocity $\left(V_{\mathrm{S}}\right)$ profile. The results produced by the MASW and the MSOR techniques were verified against independent mechanical Cone Penetration Test (CPT) and Standard Penetration Test (SPT) data. This paper identifies that the MASW and the MSOR techniques could be potentially useful and powerful tools in the evaluation of the ground compaction and general geotechnical site characterization.
\end{abstract}

\section{Introduction}

Conventional near surface geotechnical site investigations are often made by mechanical techniques (e.g. boreholes, Standard Penetration Test (SPT), Cone Penetration Test (CPT), Flat Plate Dilatometer Test (DMT), Dynamic Cone Penetrometer (DCP), and density tests, among others). These well known techniques are widely accepted as reliable methods, within the geotechnical community. However, information recovered by these techniques are localised to the point at which the test is conducted. Therefore, an adequate number of tests must be conducted at distributed points throughout the site in order to make a fair assessment, rendering the investigation both costly and protracted for an extensive site.

Recent trends have seen the adoption of non-invasive 1-D and 2-D array based surface wave techniques (e.g., SASW, MASW, MSOR, ReMi, etc) for geotechnical site investigations, which have proved to be efficient in terms of cost and time effective, compared to the conventional invasive mechanical techniques. These techniques rely on the measurement of the phase velocity dispersion curve and its inversion using a theoretical model to characterize the $V_{\mathrm{S}}$ soil profile (shear wave velocity vs. thickness of each layer) of a site. It is also increasingly recognized that the $V_{\mathrm{s}}$ profile could potentially reveal valuable information on the stiffness and associated geotechnical properties at the near surface (Lai and Rix, 1998; Xia et al., 1999). This may be inferred in part from the theoretical definition of $V_{\mathrm{s}}$ of a soil, which is given by:

$$
V_{\mathrm{s}}=\sqrt{\frac{G}{\rho}}
$$


where, $G$ is the shear modulus and $\rho$ is the bulk density. As shown in Eq. (1), the shear wave velocity is a geotechnical property that is theoretically related to the modulus of a soil. This relationship supports the notion that it is theoretically justifiable in using the $V_{\mathrm{s}}$ to measure the modulus (or stiffness) of a soil.

This paper discusses the application of the MASW and the MSOR techniques in two different geotechnical applications, (1) evaluation of compacted ground, and (2) general site investigation.

\section{Surface wave dispersion characteristics using 1-D array}

Since 1920's, characterization of the Earth's interior using seismic waves has been studied in seismology. In these earlier days, equipment for measuring seismic noise (or vibrations) was rare and expensive (Shearer, 2010). However, 1950's and 1960's saw an increased attention in their use due to the increased possibilities of numerical analysis and improvements in instrumentation for recording seismic events (Foti et al., 2011). The last two to three decades have seen the concept of using seismic waves in engineering applications receive much more attention, initially due to the introduction of the SASW technique (Nazarian and Stokoe, 1984) and then by using multiple stations (e.g., Park et al., 1999; Foti, 2000). These researchers and many others have studied the possibility of exploiting information gathered from seismic waves to characterize the ground in which they travel. These techniques rely on active ambient vibrations, which travel through the ground and are gathered by receivers at several distances from the source, to extract information on surface wave dispersion characteristics of the ground. Theoretical models developed to study wave propagation through the ground to characterize the ground profile involve making important assumptions on the composition of seismic waves. The seismic waves are composed by body waves ( $\mathrm{P}$ - and $\mathrm{S}$-waves) and surface waves (Rayleigh- and Love-waves). However, surface waves are considered as predominant in ambient vibrations when sources are at the ground surface. The combined characteristics of Rayleigh- and Love-waves can be obtained from horizontal components of microtremors gathered at the ground surface, as well as, information on Rayleigh-waves characteristics can be gathered in the vertical direction (Tokeshi et al., 2013). For this reason, the characteristics of Rayleigh waves dispersion are attempted to be retrieved at two sites by applying two non-invasive surface wave techniques, the MASW and the MSOR, using a 1-D array of geophones set up in vertical direction at the ground surface. a)

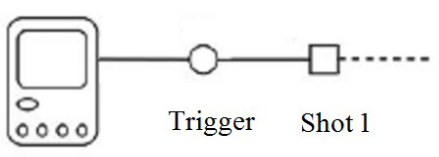

b)

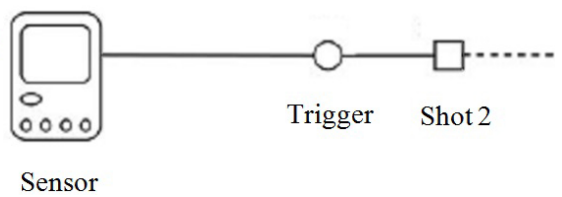

Fig. 1. Procedure for data gathering by MSOR technique.

\subsection{Multichannel analysis of surface waves (MASW) technique}

The Multichannel Analysis of Surface Waves (MASW) technique (Park et al., 1997, 1999) involves a source such as a sledgehammer impact on the ground. Vibrations generated due to sledgehammer impact are gathered by interconnected electromagnetic geophones (receivers) set up in the vertical direction and in a linear array with a constant spacing at the ground surface to obtain the experimental Rayleigh wave phase velocity dispersion curve. Usually, several shots of the sledgehammer are performed at both extremes of the array to ensure that reliable and clear dispersion curves are obtained.

\subsection{Multichannel simulation with one receiver (MSOR) technique}

The Multichannel Simulation with One Receiver (MSOR) used by Ryden et al. (2004) is a modified version of the Multichannel Analysis of Surface Waves (MASW) technique. The MSOR technique also relies on active excitation sources (e.g., hand-held hammer, Proctor hammer, etc), but it requires only a single sensor and a trigger. Instead of relying on a set of geophones for gathering vibrations by the MASW technique, the MSOR technique relies on one fixed sensor, one single moving geophone used as the trigger, and multiple shots on a steel plate at a constant distance from the trigger. Figure $1 \mathrm{a}$ and $\mathrm{b}$ show the procedure involved when moving the hammer shot and trigger locations along the 1-D array for the sensor set up at a fixed location.

\section{Evaluation of compacted ground at the Penrith Lakes}

The Penrith Lakes is located in the Hawkesbury-Nepean river floodplain (at the west of Sydney) as shown in Fig. 2. The geology of this site is composed of Bringelly shale of the Wianamatta group. The site named as Area 9 at the Penrith Lakes has an extension of about $6000 \mathrm{~m}^{2}(60 \mathrm{~m} \times 100 \mathrm{~m})$. Former surface layer of the site is weathered shale covered with sand, gravel, silt and clay with a thickness of about $13 \mathrm{~m}$. This filled ground was treated initially with dynamic compaction but the first $2 \mathrm{~m}$ of the ground surface showed 


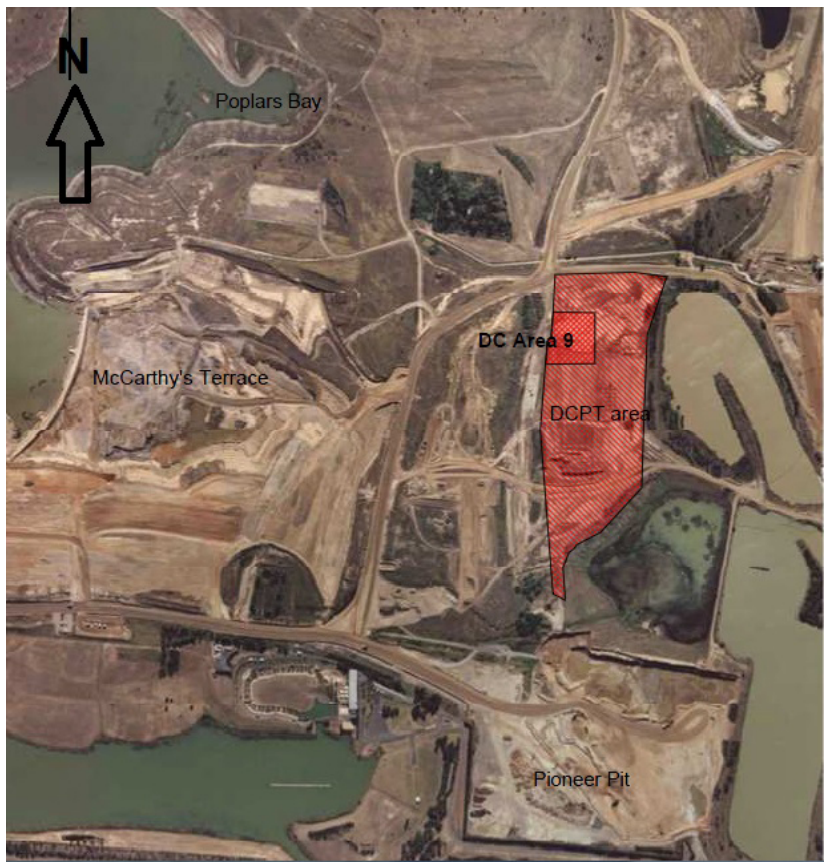

Fig. 2. Aerial view of DC site (Area 9) at the Penrith Lakes.

craters left by the $20 \mathrm{t}$ pounder dropped from $23 \mathrm{~m}$ height (a typical effect from dynamic compaction). This $2 \mathrm{~m}$ thick layer was removed and replaced by the ground treated by rolling compaction. One CPT test was performed to assess the ground improvement due to combined efforts of dynamic and subsequent rolling compaction. This independent mechanical CPT data will be compared later with estimated $V_{\mathrm{s}}$ ground profile estimated from the inversion of Rayleigh wave dispersion curve.

\subsection{Experimental Rayleigh dispersion curve by the MASW technique}

Due to the ground conditions are similar within this site, the MASW technique was applied here. The overall assessment of the compacted ground was attempted using six test lines of $60 \mathrm{~m}$ length distributed uniformly along the Area 9 as illustrated in Fig. 3. Twenty one single component (vertical) geophones at a spacing of $3 \mathrm{~m}$ were used in each 1-D array. Vertical hits of a $3.6 \mathrm{~kg}(8 \mathrm{lb}$.) sledgehammer against a solid steel plate at a distance of $5 \mathrm{~m}$ from each end of the array were used to generate mainly Rayleigh wave vibrations in the ground.

The data from the geophones were gathered by one laptop via a multichannel digital seismic acquisition system (Soilspy Rosina from Micromed). The actively generated ambient vibrations were recorded for three seconds per shot at a sampling rate of $512 \mathrm{~Hz}$. Figure 4 shows a sample of the dromochrones for $1 \mathrm{~s}$ gathered by 21 vertical geophones. These dromochrones contain mainly information on Rayleigh waves which are a combination of $\mathrm{P}$ - and

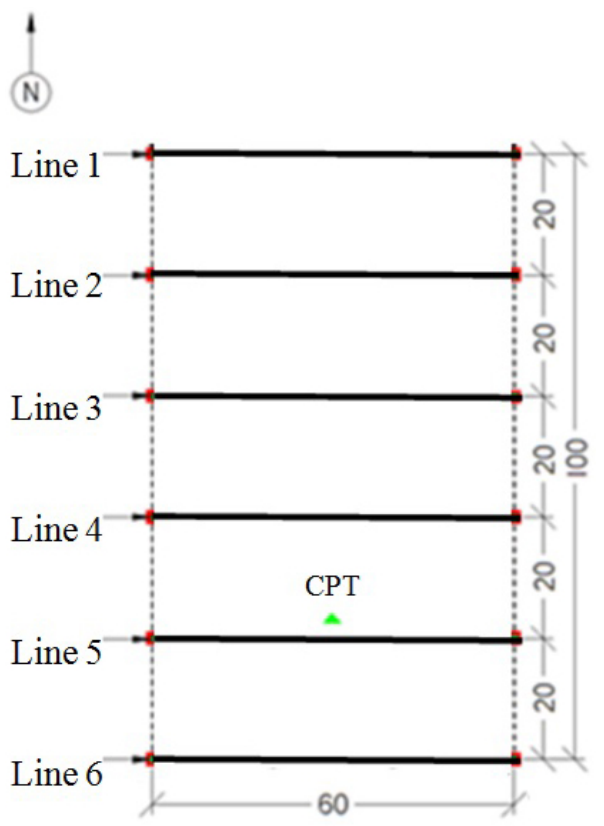

Fig. 3. Location of MASW line tests (solid lines) and CPT test (indicated by triangule) in Area 9 at DC site.

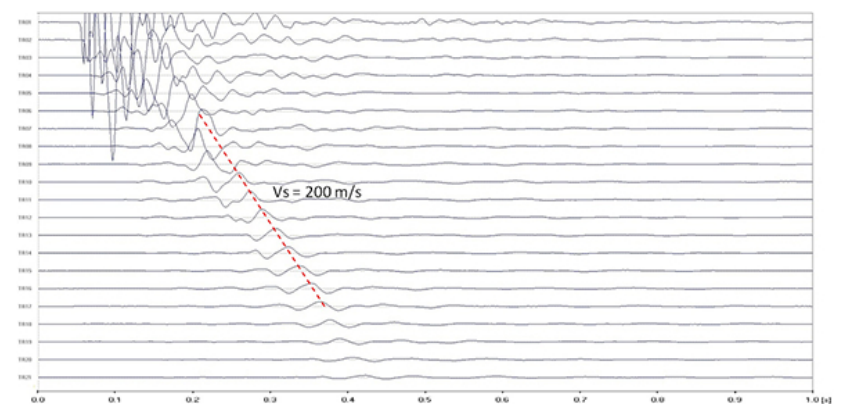

Fig. 4. Dromochrones gathered by 21 geophones at a spacing of $3 \mathrm{~m}$ (MASW technique).

SV-waves. The dashed line connecting large amplitudes of waveforms represents roughly the SV waves velocity of $200 \mathrm{~m} \mathrm{~s}^{-1}$. This value would represent the shear wave velocity of some predominant layers below the survey line.

The experimental Rayleigh waves dispersion curve was obtained by picking points of maximum energy from the frequency-phase velocity (f-c) spectra using the Grilla software v.6.1 from Micromed. Figure 5 shows the MASW Rayleigh dispersion curve obtained for Line 5 as a function of the phase velocity and the wavelength; as the wavelength reflects more closely the depth of penetration. It can be seen that this dispersion curve is undulating, which would mean the presence of some "velocity inversion" (a layer of lower shear wave velocity than the upper layer). In fact, this is true as a result of the ground compaction works carried out in this site (as mentioned in Sect. 3). 


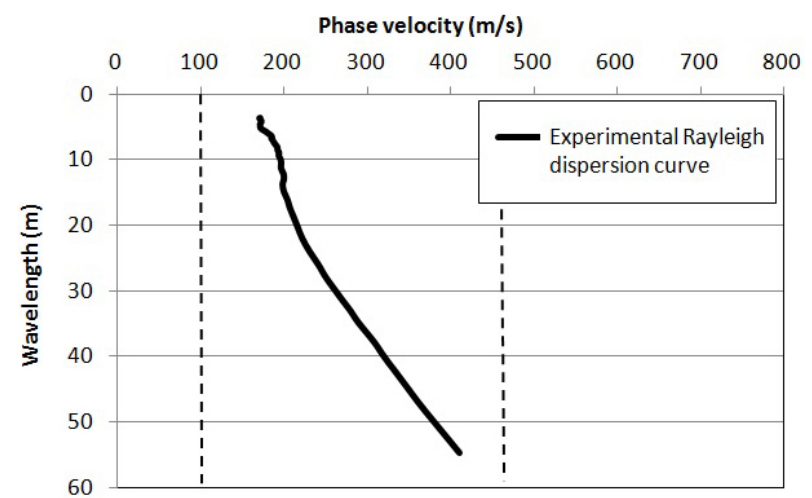

Fig. 5. Experimental MASW Rayleigh dispersion curve obtained for Line 5 in Area 9 at DC site. Vertical dashed lines show the shear wave velocity range used for layers in inversion.

Table 1. Ranges used in parameters for the MASW dispersion inversion.

\begin{tabular}{|c|c|c|c|c|c|c|}
\hline \multirow[t]{2}{*}{ Layer } & \multicolumn{2}{|c|}{$\begin{array}{l}\text { Thickness } \\
H(\mathrm{~m})\end{array}$} & \multicolumn{2}{|c|}{$\begin{array}{l}\text { Sher wave velocity } \\
\qquad V_{\mathrm{s}}\left(\mathrm{m} \mathrm{s}^{-1}\right)\end{array}$} & \multicolumn{2}{|c|}{$\begin{array}{c}\text { Poisson's ratio } \\
v \\
\end{array}$} \\
\hline & Min & Max & Min & Max & Min & Max \\
\hline $\begin{array}{l}1 \\
2 \\
3 \\
4 \\
5 \\
6\end{array}$ & 0.5 & 10 & 100 & 450 & 0.3 & 0.49 \\
\hline Half-space & & nity & 450 & 750 & & \\
\hline
\end{tabular}

\subsection{Estimation of $V_{\mathrm{s}}$ ground profile by global Monte Carlo approach}

The MASW Rayleigh dispersion curve was inverted following the methodology proposed by Tokeshi et al. (2008). Six layers overlying a half-space (bedrock) with random values for three physical soil properties: thickness, shear wave velocity and Poisson's ratio, were used in the global Monte Carlo search (Table 1). Vertical dashed lines in Fig. 5 show the shear wave velocity range used in Table 1 . The maximum thickness of $10 \mathrm{~m}$ for all layers was obtained after dividing the maximum wavelength of $60 \mathrm{~m}$ by 6 layers. The shear wave velocity range for the half-space was assumed considering it consists of medium grained clayey sand and weathered shale. According to results reported by Bauer (2007), the $V_{\mathrm{s}}$-values of weathered shale can be less than $600 \mathrm{~m} / \mathrm{s}$. In consequence, a margin of $\pm 150 \mathrm{~m} \mathrm{~s}^{-1}$ around $600 \mathrm{~m} \mathrm{~s}^{-1}$ was used.

The P-wave velocity, $V_{\mathrm{P}}$, was calculated by Eq. (2).

$V_{\mathrm{P}}=V_{\mathrm{s}}\left(\frac{1-v}{0.5-v}\right)^{0.5}$

where, $v$ is the Poisson's ratio.
The density was calculated using the Eq. (3); an empirical relationship proposed by Gardner et al. (1974).

$\rho=0.31 V_{\mathrm{P}}^{0.25}$

where, $\rho$ is the density in $\left(\mathrm{t} \mathrm{m}^{-3}\right)$.

Additionally, due to the $V_{\mathrm{s}}$ ground models from inversion can be non-compatible with the actual ground condition described in Sect. 3, which is supported by the undulating characteristics of experimental Rayleigh wave dispersion curve shown in Fig. 5, the following rules were applied in the selection of $V_{\mathrm{s}}$ ground models for having the presence of the "velocity inversion".

a. $V_{\mathrm{S}}$ of the second layer is less than or equal to the $V_{\mathrm{s}}$ of first layer.

b. $V_{\mathrm{S}}$ of the third layer is greater than or equal to the $V_{\mathrm{s}}$ of second layer.

c. $V_{\mathrm{s}}$ of the fourth layer is less than or equal to the $V_{\mathrm{s}}$ of third layer.

d. $V_{\mathrm{S}}$ of the fifth layer is greater than or equal to the $V_{\mathrm{s}}$ of fourth layer.

e. $V_{\mathrm{s}}$ of the sixth layer is less than or equal to the $V_{\mathrm{s}}$ of fifth layer.

These conditions were assumed considering that the effect of dynamic ground compaction does not reach depths larger than $10 \mathrm{~m}$, and that the shallow surface layer of about $2 \mathrm{~m}$ thickness was improved with rolling compaction (described in Sect. 3).

Then, the theoretical dispersion curve for each ground model was calculated according to a theoretical model developed by Haskell (1953), and their misfit with the experimental curve was calculated by Eq. (4).

misfit $=\sum_{j=1}^{n}\left[\left(c_{\mathrm{o}_{j}}-c_{\mathrm{t}_{j}}\right) / c_{\mathrm{o}_{j}}\right]^{2} / n$

where, $n$ is the number of frequencies assessed in the dispersion curve, $c_{\mathrm{t}_{j}}$ is the theoretical phase velocity, and $c_{\mathrm{o}_{j}}$ is the experimental phase velocity, respectively for the $j$-th frequency.

The inversion process concluded when the minimum misfit was lower than 0.01. Figure 6 shows the comparison between the theoretical and the experimental MASW phase velocity dispersion (white dashed line) curves, where the goodness-of-fit between both is evident.

To normalize the effect of effective stress on CPT tip resistance $q_{c}$, the Eq. (5) proposed by Robertson and Wride (1998) was applied.

$q_{\mathrm{c} 1}=q_{\mathrm{c}}\left(\frac{P_{\mathrm{a}}}{\sigma_{\mathrm{v}}^{\prime}}\right)^{0.5}$ 


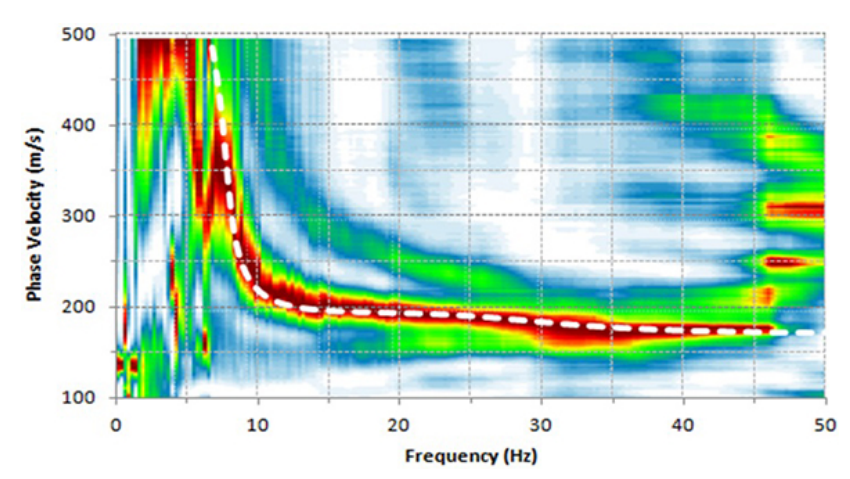

Fig. 6. Comparison between experimental MASW- and theoretical (white dashed line) Rayleigh dispersion curves.

where, $q_{\mathrm{c} 1}$ is the normalized cone penetration resistance in $\mathrm{kPa}, \sigma_{\mathrm{v}}^{\prime}$ is the vertical effective stress in $\mathrm{kPa}, P_{\mathrm{a}}$ is the reference effective pressure $\left(P_{\mathrm{a}}=100 \mathrm{kPa}\right)$, and the correction factor $\left(P_{\mathrm{a}} / \sigma_{\mathrm{v}}^{\prime}\right)^{0.5}$ has a maximum value of 2 . Also, the normalized shear wave velocity $V_{s 1}$ was calculated by Eq. (6) applied by Wride et al. (2000):

$V_{\mathrm{s} 1}=V_{\mathrm{s}}\left(\frac{P_{\mathrm{a}}}{\sigma_{\mathrm{v}}^{\prime}}\right)^{0.25}$

where, $V_{\mathrm{s}}$ is the non-normalized shear wave velocity.

The normalized $V_{\mathrm{s} 1}$ ground model obtained from the MASW inversion was verified by available normalized independent mechanical CPT $-q_{\mathrm{c} 1}$ data (Fig. 7). Good correlation between the MASW estimated $V_{\mathrm{s}}$ ground model and the invasive CPT cone penetration resistance data was achieved, where the effect of the dynamic compaction has reached up to $8 \mathrm{~m}$ depth. Also, it is important to note that the normalized shear wave velocity estimated for the upper $2 \mathrm{~m}$ reflects the ground improvement of the subsequent application of rolling compaction technique. Finally, the experimental Rayleigh dispersion curve normalized by Eq. (6) is also superposed in Fig. 7 to show that even though the dispersion curve does not fit well with the normalized ground model, $V_{\mathrm{s} 1}$, due to complex ground conditions, the depth of the ground model and the value corresponding to one-fourth of wavelength are in good correlation.

\section{Geotechnical site characterization at UWS Kingswood site}

The site in study is located in Kingswood campus of the University of Western Sydney (UWS) as shown in Fig. 8. The geology of this site is composed of Bringelly shale of the Wianamatta group. Available borehole data in the assessed area (black point in Fig. 8) shows the upper surface of about $1.2 \mathrm{~m}$ thickness consisting of silty clay fill mixed with root fibers, and beneath this fill soil, the presence of clayed sand soil layers. Then, deeper silty clays were classified as

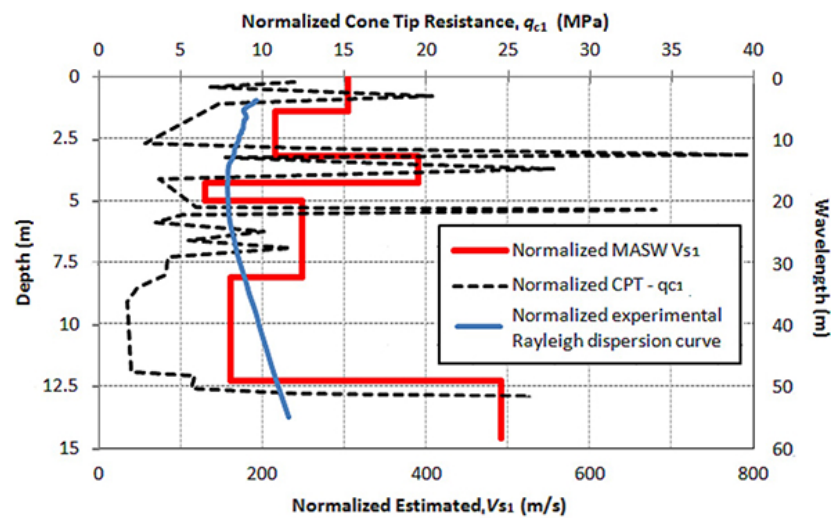

Fig. 7. Comparison between the normalized ground model $V_{\mathrm{s} 1}$ obtained from MASW dispersion inversion, the normalized mechanical CPT $q_{\mathrm{c} 1}$ data, and the superposed normalized Rayleigh dispersion curve.

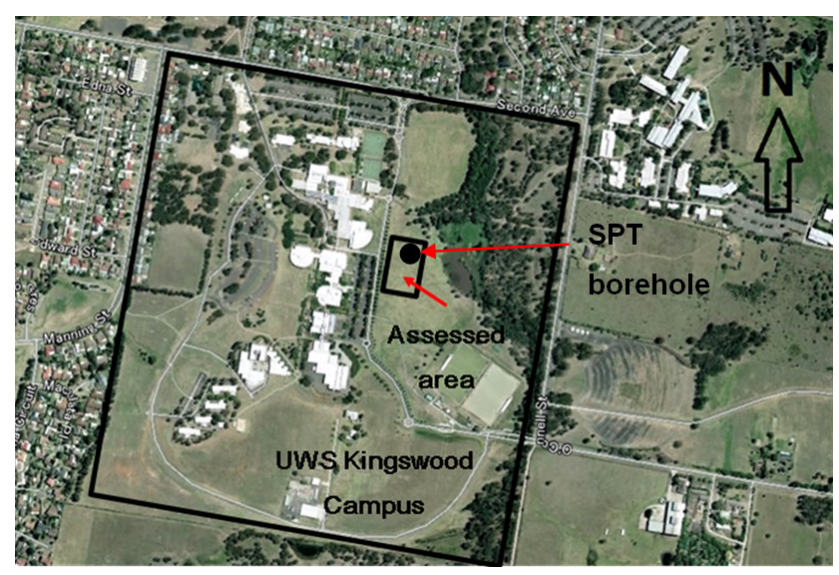

Fig. 8. Aerial view of the UWS Kingswood campus showing the location of SPT borehole in the assessed area.

residual soils due to some contained remnants of shale structure. From $8.8 \mathrm{~m}$ depth, low strength weathered shale was founded.

\subsection{Experimental Rayleigh dispersion curve by the MSOR technique}

Due to irregular ground conditions in this site (depth of the bedrock varying from 3 to $10 \mathrm{~m}$ ), the MSOR technique was applied here. As mentioned in Sect. 2.2, the vibrations are gathered only by one sensor fixed at the location of interest, which would let us gather information on Rayleigh dispersion characteristics at the observation point. Also, this MSOR technique can be applied to assess "uniform" ground conditions (such as the Penrith Lakes site assessed in Sect. 3) in case the multichannel acquisition system is not available.

The pseudo linear array of 15 vertical component sensors at a spacing of $1 \mathrm{~m}$ was set up along the North-South axis of the available borehole. To generate mainly Rayleigh wave 


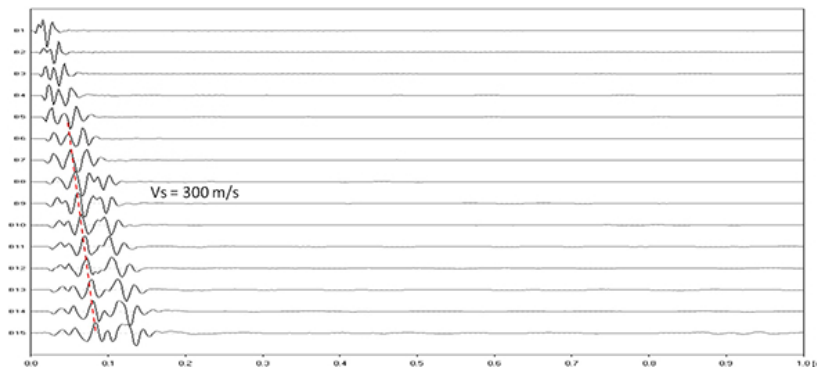

Fig. 9. Dromochrones gathered by 15 synthetic geophones at a spacing of $1 \mathrm{~m}$ (MSOR technique).

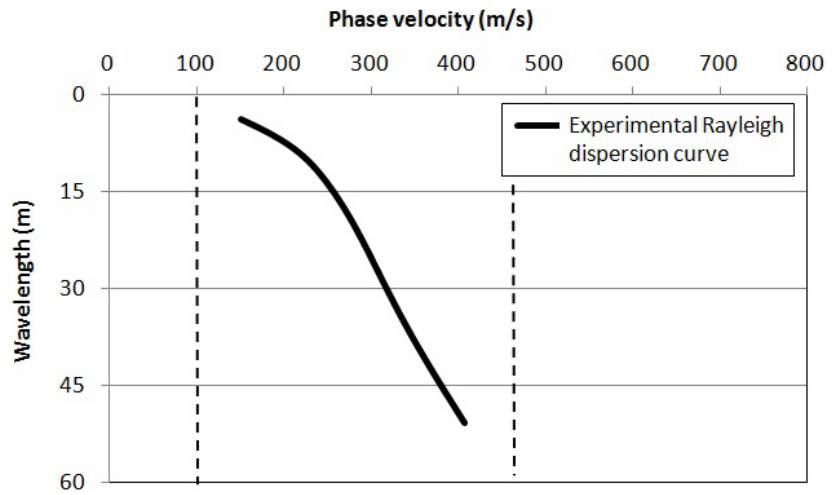

Fig. 10. Experimental MSOR Rayleigh dispersion curve obtained at the assessed site. Vertical dashed lines show the shear wave velocity range used for layers in inversion.

vibrations in the ground surface, a $3.6 \mathrm{~kg}$ ( $8 \mathrm{lb}$.) sledgehammer was used to strike vertically against a solid steel plate set up at a distance of $1 \mathrm{~m}$ from the trigger location (Fig. 1). Active microtremors from these shots were recorded continuously at a sampling rate of $512 \mathrm{~Hz}$ by one 3 -component ( 2 horizontal and 1 vertical) high-resolution electro-dynamic sensor (Tromino ${ }^{\mathrm{TM}}$ from Micromed) fixed close to the borehole location.

Figure 9 shows a sample of the dromochrones for $1 \mathrm{~s}$ gathered by 15 synthetic geophones set up in vertical direction (the vertical component of the fixed sensor). The dashed line connecting large amplitudes of waveforms represents roughly the SV waves velocity of $300 \mathrm{~m} \mathrm{~s}^{-1}$. This value would represent the shear wave velocity of some predominant layer below the survey line.

The experimental MSOR Rayleigh dispersion curve was generated using the commercial software from Micromed mentioned in Sect. 3.1. Figure 10 shows the MSOR Rayleigh dispersion curve (phase velocity vs wavelength) obtained at the assessed site. It can be seen that this dispersion curve does not show undulations such as the one displayed in Fig. 5 at the Penrith Lakes site, which would mean that there is no presence of "velocity inversion" and that the value of the shear wave velocity of layers would increase with the depth.
Table 2. Ranges used in parameters for the MSOR dispersion inversion.

\begin{tabular}{|c|c|c|c|c|c|c|}
\hline \multirow[t]{2}{*}{ Layer } & \multicolumn{2}{|c|}{$\begin{array}{c}\text { Thickness } \\
H(\mathrm{~m})\end{array}$} & \multicolumn{2}{|c|}{$\begin{array}{l}\text { Sher wave velocity } \\
\qquad V_{\mathrm{s}}\left(\mathrm{m} \mathrm{s}^{-1}\right)\end{array}$} & \multicolumn{2}{|c|}{$\begin{array}{c}\text { Poisson's ratio } \\
v\end{array}$} \\
\hline & Min & Max & Min & Max & Min & Max \\
\hline $\begin{array}{l}1 \\
2 \\
3 \\
4\end{array}$ & 0.5 & 15 & 100 & 450 & 0.3 & 0.49 \\
\hline Half-space & & iity & 600 & 1000 & & \\
\hline
\end{tabular}

\subsection{Estimation of $V_{\mathrm{s}}$ ground profile from MSOR disper- sion inversion}

The MSOR Rayleigh dispersion curve was inverted following similar methodology explained in Sect. 3.2, but with the exception of the rules applied in the selection of $V_{\mathrm{s}}$ ground models at the previous site. Based on the phase dispersion curve displayed in Fig. 10, the rule applied here was that the $V_{\mathrm{s}}$-value of subsequent below layer is equal or greater than the $V_{\mathrm{s}}$-value of the upper layer.

Table 2 shows the random values of the three variables used for the ground model consisting of 4 layers overlying a half-space (bedrock). Vertical dashed lines in Fig. 10 display the shear wave velocity range of shallow layers shown in Table 2. The maximum thickness of $15 \mathrm{~m}$ for the four layers was obtained after dividing the maximum wavelength of $60 \mathrm{~m}$ by 4 layers. The shear wave velocity range for the halfspace was assumed considering it is weathered shale of low strength (Sect. 4). Again, the P-wave velocity and the density were respectively calculated using Eq. (2) and Eq. (3).

The theoretical dispersion curve for each ground model was calculated according to the theoretical model developed by Haskell (1953), and their misfit with the experimental curve was calculated by Eq. (4). The inversion process concluded when the minimum misfit was lower than 0.01 . Figure 11 shows the goodness-of-fit between experimental MSOR dispersion curve and theoretical dispersion curve (white dashed line) of the estimated $V_{\mathrm{s}}$ ground model.

Figure 12 shows the $V_{\mathrm{s}}$ ground model estimated from MSOR Rayleigh dispersion inversion in comparison with the $V_{\mathrm{S}}$-values estimated from average SPT- $N$-value of layers using the following simplified equations (Towhata, 2008):

$V_{\mathrm{s}}=80 N^{1 / 3} \quad\left(\mathrm{~m} \mathrm{~s}^{-1}\right) \quad$ for sand and

$V_{\mathrm{s}}=100 \mathrm{~N}^{1 / 3} \quad\left(\mathrm{~m} \mathrm{~s}^{-1}\right)$ for clay

The $V_{\mathrm{s}}$-value of $100 \mathrm{~m} \mathrm{~s}^{-1}$ was adopted for the fill layer because it was a silty clay of low plasticity mixed with root fibers and fine to medium grained sand. The $V_{\mathrm{s}}$-values for the second and third layers of $215 \mathrm{~m} \mathrm{~s}^{-1}$ and $275 \mathrm{~m} \mathrm{~s}^{-1}$ were obtained from Eq. (7) when $N=20$ for sandy layers and when $N=20.7$ for clayey layers, respectively. It can be seen 


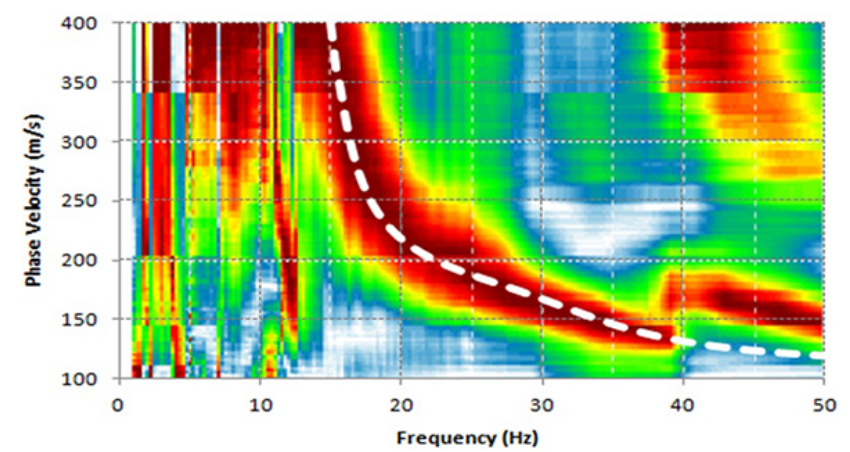

Fig. 11. Comparison between experimental MSOR- and theoretical (white dashed line) Rayleigh dispersion curves.

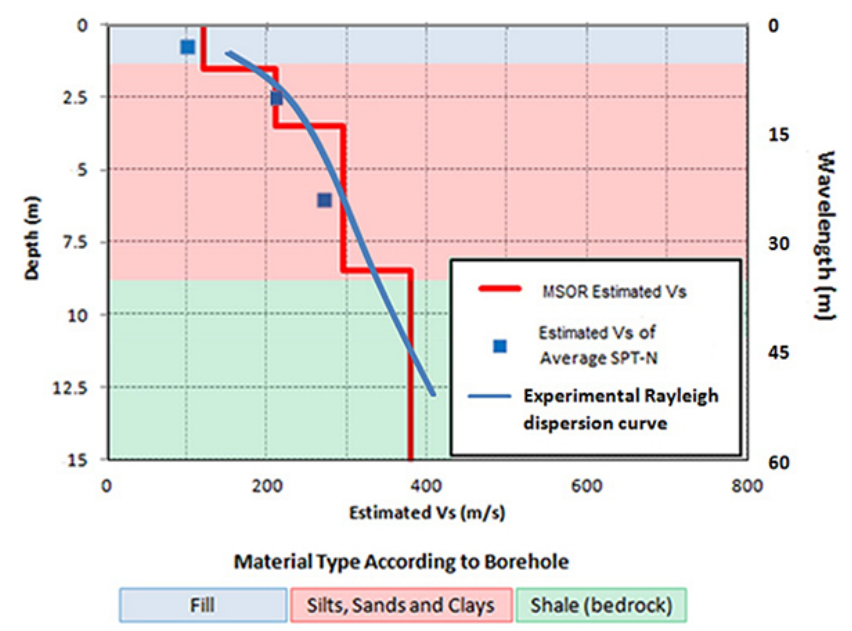

Fig. 12. Comparison between the MSOR estimated $V_{\mathrm{S}}$ ground model, the estimated $V_{\mathrm{S}}$ from SPT- $N$, the borehole data, and the superposed Rayleigh dispersion curve.

that the values of shear wave velocity of corresponding layers are in fair agreement with the one estimated from SPT data. Also, the experimental Rayleigh dispersion curve of Fig. 10 traverses the MSOR estimated $V_{\mathrm{s}}$ ground model in Fig. 12, when the value of one-fourth of wavelength is applied in the superposition. The correlation observed here between the experimental Rayleigh dispersion curve (phase velocity vs one-fourth wavelength) and the $V_{\mathrm{s}}$ ground model (shear wave velocity vs. depth) estimated from Rayleigh dispersion inversion would give clues on the characteristics of $V_{\mathrm{s}}$ ground models to be inferred from the inversion.

\section{Conclusions}

The paper has shown the successful application of the MASW and the MSOR techniques in two different geotechnical applications, (1) evaluation of compacted ground, and (2) geotechnical site investigation. These non-invasive techniques allowed for the estimation of the $V_{\mathrm{s}}$ ground pro- file in a time efficient and cost effective manner compared to the invasive techniques. The inferred results from MASW and MSOR techniques were verified against independent mechanical CPT- $q_{\mathrm{c}}$ and SPT- $N$ data, respectively. Correlation between the experimental Rayleigh dispersion curve (phase velocity vs one-fourth wavelength) and the $V_{\mathrm{s}}$ ground model (shear wave velocity vs. depth) estimated from Rayleigh dispersion inversion was observed, and they confirm that these non-invasive techniques are useful in evaluating the $V_{\mathrm{s}}$ ground profile.

Acknowledgements. The authors would like to express their gratitude to the Australian Research Council, Penrith Lakes Development Corporation and Coffey Geotechnics for their generous support in this study.

Edited by: C. Fernandez-Baca-Vidal

Reviewed by: C. Park and one anonymous referee

\section{References}

Bauer, R. A.: Shear Wave Velocity, Geology and Geotechnical Data of Earth Materials in the Central U.S. Urban Hazard Mapping Areas, Final Technical Report, External Grant Award Number 06-HQ-GR-0192, 2007.

Foti, S.: Multistation methods for geotechnical characterization using surface waves, PhD Thesis, Politecnico di Torino, Italy, 2000.

Foti, S., Parolai, S., Albarello, D., and Picozzi, M.: Application of surface-wave methods for seismic site characterization, Surveys in Geophysics, 32, 777-825, 2011.

Gardner, G. H. F., Gardner, L. W., and Gregory, A. R.: Formation velocity and density; the diagnostic basics for stratigraphic traps, Geophysics, 39, 770-780, 1974.

Haskell, N. A.: The dispersion of surface waves on multilayered media, Bulletin of the Seismological Society of America, 43, 1734, 1953.

Lai, C. G. and Rix, G. J.: Simultaneous inversion of Rayleigh phase velocity and attenuation for near-surface site characterization, Georgia Institute of Technology, 1998.

Nazarian, S. and Stokoe, K. H.: In situ shear wave velocities from spectral analysis of surface waves, 8th World Conference on Earthquake Engineering, San Francisco, USA, 3, 31-38, 1984.

Park, C. B., Miller, R. D., and Xia, J.: Multi-channel analysis of surface waves (MASW) "A summary report of technical aspects, experimental results, and perspective", Kansas Geological Survey, 1997.

Park, C. B., Miller, R. D., and Xia, J.: Multichannel analysis of surface waves, Geophysics, 64, 800-808, 1999.

Robertson, P. K. and Wride, C. E.: Evaluating cyclic liquefaction potential using the cone penetration test, Can. Geotech. J., 35, 442-459, 1998.

Ryden, N., Park, C. B., Ulriksen, P., and Miller, R. D.: Multimodal approach to seismic pavement testing, J. Geotech. Geoenviron., 130, 636-645, 2004.

Shearer, P. M.: Introduction to seismology: The wave equation and body waves, unpublished, Institute of Geophysics and Planetary 
Physics, Scipps Institution of Oceanography, University of California, San Diego, 2010.

Tokeshi, K., Karkee, M., and Cuadra, C.: Estimation of Vs profile using its natural frequency and Rayleigh-wave dispersion characteristics, Adv. Geosci., 14, 75-77, doi:10.5194/adgeo-14-752008, 2008.

Tokeshi, K., Leo, C. J., and Liyanapahirana, S.: Comparison of ground models estimated from surface wave inversion using synthetic microtremors, Soil Dyn. Earthq. Eng., 49, 19-26, 2013.

Towhata, I.: Geotechnical Earthquake Engineering, Springer Series in Geomechanics and Geoengineering, Springer-Verlag Berlin Heidelberg, 2008.
Xia, J., Miller, R. D., and Park, C. B.: Estimation of near-surface shear-wave velocity by inversion of Rayleigh waves, Geophysics, 64, 691-700, 1999.

Wride, C. E., Robertson, P. K., Biggar, K. W., Campanella, R. G., Hofmann, B. A., Hughes, J. M. O., Kupper, A., and Woeller, D. J.: Interpretation of in situ test results from the CANLEX sites, Can. Geotech. J., 37, 505-529, 2000. 